\title{
Com a palavra, duas Coordenações de Cursos
}

\section{Bahia}

Quais são os principuis problemas a dificuldades entrentados pelos Cursos de graduaçäo? Quais as propostas para superá-los? A estas duas questöes responderam a Coordenaçäo do Curso de Psicologia da Universidade Federal de Pernambuco e o professor Antonio Marcos Chaves, Coordenador do Colegiado do Curso de Psicologia da Universidade Federal da Babia.

- Colegiado dos Cursos de Psicologia há muito tem verificado a defasagem do currículo que é óferecido aos alunos para a habilitação $\mathrm{cm}$ Bacharelado, Licenciatura e Formaçāo de Psicólogo. Estas deficiências e defasagens sảo constatadas confrontando o currículo e conseqüente formação oferecida e a realidade regional. Alguns aspecros do currículo atual sāo evidentes, tais como:

a) formaçżo orientada para o exercício da Psicologia clínica, com ênfase na abordagem psicanalítica;

b) apenas uma disciplina específica para o preparo do exercício da Psicologia Industrial $e$ ou organizacional.

c) nenhuma disciplina específica voltada para o preparo do Psicólogo Escolar;

d) nenhuma disciplina que subsidie o esrudante para atuaçōes coletivas, no âmbito de comunidades, associaçốes $e$ ou instituiçōes;

e) os estágios supervisionados são restritos às trés áreas clássicas: psicologia clínica, psicologia escolar e psicologia industrial.

f) os estudantes só entram em contato com disciplinas que permitem uma aproximaçäo às formas de raciocinio científi$\infty$, de produção, análise e que despertam a curiosidade científica, ou seja, a de investigar, nos dois últimos periodos letivos do curso de Bacharelado;

B) o elenco das disciplinas optativas é muito restrito: treze disciplinas, dentre as quais o aluno é obrigado a cursar cinco. Vale ressaltar que em média oferece-se a cada semestre letivo apenas seis delas, sem muita variaçāo, o que as torna, praticamente, obrigatórias.

Qual tem sido, grosso modo, o perfil do estudante ou do profissional formado? Os estudantes a partir do $3^{\circ}$ semestre iniciam a sua carceira para a formaçāo clínica com vistas a uma prática psicanalíicica, começam a estudar Psicologia da Personalidade I e II, geralmente discutindo conteúdos psicanalíticos, que sâo aprofunda. dos em Teorias da Personalidade I. Neste momento em que os estudantes já refletiram 180 horas sobre as obras de Freud e seus seguidores e que muitos, precipitadamente, já consideram esta a sua opçāo teórica, deparam-se com o gestaltismo em Teorias da Personalidade II, e com o behaviorismo em Teorias da Personalidade III. Fora toda esta preparaçäo clínica, os alunos passam 375 horas do curso estudando Técnicas de Exame e Aconselhamento Psjcológico, ministrados por professores psicanalistas e 360 horas estudando psicopacologia dentro de um modelo médico. Parece claro que no final de todos estes estudos a opção em termos de ârea de estágio supervisionado seja, predominantemente, na área clínica e dentro da orientaçāo psicanalítica.

Por tudo isso e claro reflexo da formaçăo oferecida pelo curso, mesmo as áreas clássicas de atuação como a psicologia escolar $e$ a psicologia industrial ficam relegadas, possibilidades de atuaçăo comunitária $e$ ou institucionais ficam mais distantes ainda.

Outro grande problema é no que se refere à formação científica dos profissionais, pois na medida em que o estudante opta, prematuramente, pela atuaçīo profissional em Psicologia Clínica e só se depara com discussós metodológicas relativas à ciência, no final do curso, o interesse do aluno centra-se em aprender técnicas que viabilizem a sua atuaç̄ono protissional, do que na análise sistemática das teorias psicológicas com base na fundamentacão científica que as sustenta.

A decortência de tudo isso é que se coloca à disposiçăo da comunidade uma massa de profissionais que, na maior pazte das vezes, vai enclausurar-se em seus consultórios particulares para atender uma clientela "seleta" $e$ uma cidade com uma população pobre, com centenas de escolas, com inúmeras instituiç̄es e com uma indústria em expansäo, que nito dispöe de profissionais psicólogos para atender as suas demandas.

Constatadas estas deficièncias e vieses na formaçāo em Psicologia oferecida por este curso, o Colegiado tem encarninhado árduas discussores no sentido de:

a) priorizar a formaço científice des de $o$ inicio do curso, necessariamente $6 b$ via para o Bacharel em Psicologia, e indispensável para a formsça do profissional competente e consequiente;

b) diversificar a oferta das disciplinas visando atender 20 objetivos de um curac de graduaçäo com vistes à formaçio gera do profissional em Psicologia e sem sobrecarga para qualquer enfoque reórico;

c) montar cadeias de disciplines que viabilizem a formaça do durante todo o curso, visando as seguintes terminalidades: 1) Bacharel em Psicologia, 2) Professor de ensino de $2^{\circ}$ grau, 3) Psicólogo clínico psicólogo escolar, psicólogo industrial e ou organizacional e psicologo para aruar em instituiç̋es e ou psicologia social comunitária.

Perseguindo este objetivo de reformulaçäo, neste ano produziu-se, inicialmente, uma proposta de reformulaço do $1^{\circ}$ ciclo de estudos que compreender of dois primeiros semestres letivos e ters $\infty$ mo objetivo fornecer condiçes para o estudante ter uma formaço básica e geral para o conseqüente estudo especifico da Psicologia. Esta proposta esté em processo de discussto e aprovacia no Colegiado - sugere como conjunto de estudos básicos as disciplinas: Introduçẫo a Filosofí, Introduçio Antropologia, Historia d Psicologia, Fundamentos de Psicologia Neuroanatomia, Introduço a Sociologia, Psicologia Geral, Introduçāo a Metodologia Cientifica, Métodos Quantitativos, Fisiologia e Genética Aplicada.

Assin que este processo com relaçio ao $1^{\circ}$ Ciclo for concluido, partir-se- 4 para a reformulaçāo do $2^{\circ}$ Ciclo. 


\section{Pemambuco}

A exemplo do que vem ocorrendo a nivel nacional, o curso de Psicologia da Universidade Federal de Pernambuco com habilitaçōes em bacharelado e formaço de psicologo, ressente-se de algumas dificuldades en sua estrutura organizativa.

Em funcīo de soliciraço da próreitoria acad́tinica para que procedếsse. mos a uma ampla svaliaça do curso, resolvemos que esta deveria culminar com uma reforma curriculer.

A avaliacio teve inicio no primeiro semestre de 1988 e escollemos como metodo de trabalho a divisto do curso em 4 áreas (paicologia do trabalho, clínica, escolar e pesquisa) e o agrupanento dos professores por átea de conhecimento, havendo para cada uma das 4 áreas um coordenador.

Cada grupo, aprementou ao pleno do Departamento um documento com 0 diagnóstico da situaçāo da sua área no curso e ainda sugestōes de como enfrentar os problemes detectados.

A participacão estudantil deu-se atra$\nabla$ s da ecolha de um representante por periodo letivo totalizando 10 escudantes com direito a roz $e$ voto. Os demais alunos podium participar das reuniōes apenas com direito a voz.

Os estudantes realizaram paralela mente seus estudos sobre a curso $c$ apresentaram tambsm sugestóes para possíveis mudangas. Aposs a apresentação e debates das 4 freas passou-ste a discutit as novas proposeas de entencas por disciplinas, tanto eletivas como as do curriculo minimo.

No presente momento há uma couris s $x_{0}$ de sistematizacão elaborando uma no. va proposta de organização do curso e de sua grade curricular, que deverí ser apresentada ainda este mes em reuniao do pleno do Departamento.

Das dificuldades ericontradas ao longo do processo avaliativo podemos destacar, néste momento, as seguintes:

1. Desconexão entre as disciplinas

1.1 Redefinicăo dos conteúdos das disciplinas envolvendo os processos básicos, incluindo de forma mais abrangente os procerssos de memória, linguagem e comunicacto e os processos cognitivos de modo mais amplo.
1.2. Redefiniçäo dos pré-requisitos em relaçāo a maioria das disciplinas cons. tantes da grade curricular.

1.3. Falra de integração dos protessores no plancjamento de seus cursos, necessitando coordenar sua açóes no sentido de entender por que e para que se estudam determinados conteídos e/ou pesquisas.

1.4. Escassez de produção de conhecimento na intersecção dos aspectos aferivos, cognitivos e social, dificultando a articulaç̃o desses aspectos. Acrescence-se a isto, a necessidade de maior insegraçāo entre algumas disciplinas que se relacionam com determinada área, cvitando-se assim 2 departamentalização do conhecimento.

2. Disciplinas predominantemence na área clínica e ausência de prática.

Tradicionalmence, observa-se uma uraior concentracão no acendimento psicoterápico e no psicoldiagnóstico, a ponto da representação social do clínico ser expressa como aquela que desempenha exclusivamente essas funcôes.

$\mathrm{Na}$ perspectiva de que nosso curso superdimensiona a atividade psicoterápica, observa-se tambem uma enfase nos conteúdos tebricos em detrimento de atividades ptóticas.

A formaçăo do psicologo do trabalho e tortemente marcoda por conteúdos da área clínica, o que poderia ser enriquecedos, se este fato nào ocorresse em detrimento dos conteúdos específicos da śrea de trabalho.

3. Curriculo fora da realidade sóciocultural e dicotomia entre teoria e prítica.

Com a diversificaço e amplitude dos temas dentro da paicologia industrial, hâ uma necessidade dos cursos de psicologia acompanharem estes avanços produzidos pelos estudos desenvolvidos pelos profissionais envolvidos com a área. Se no seu inicio a psicologia, principalmente $a$ industrial, voltava-te prioritariamente para o individuo, como forca produtiva, visando adaprá-lo a situaç̧o de trabalho, na atualidede há una preocupacão com a organizaçzo e com o indivíduo buscando, assim, uma visăo sistêmica.

\section{Dicotomia entre teoria e prática}

- Quando da implantação do curso, a prática na área de psicologia do traba. tho era preponderantemente voltada para a seleção de pessoal e/ou orientaçäo profissional. A realidade hoje é outrs, a psicologia estuda c ajuda o homem em seu trabalho em quaisquer situaçōes e nāo só $\mathrm{n} \mathbf{z}$ indústria. Os avancos devem-se a pesquisa e novas reflexōes sobre o tema.

5. Currículo fora da realidade sócio- cultueal

- Os tínulos se diversificaram - psicologia organizacional, psicologia do trabalho, psicologia social das organizagōes, psicologia das relaçōes humanes no trabatho etc. Esta diversificacto mostra bem a amplitude que a frea vem atingindo.

- Se antes a psicologia industrial se voltava, prioritariamente, para o individuo como força produtiva visando adaptk-to a situação de crabalho, hoje, sem esquecer o individuo, prescupe com a organizaça como um todo numa visło sistêmica.

- Sugere criaça de novas disciplinas e formação de grupos de trabalho capacitado, preocupado com o ensino, a produça de pesquise e a extensazo.

6. Impossibilidade de aprotundar questōes.

Algumas propostas para neutralizar as dificuldades detectadas.

1. Nova perspectiva para a psicologia, exigindo uma açio interdieciplinar, o que demande uma atualizacto na formaço profissional e uponte os direcajo do trabatho do psicólogo como ligado a promosto da saúde nas suas múltiplas e complexas decerminacoes.

2. Propiciar ao aluno uma formação mais abrangente visando astegurar-lhe habilitaç3o pata responder 200 novos desafios de profissto.

Maior integraço entre as diferentes areas de conhecimento principalmente com a psicologin social.

Objetive de formar um profissional que se idencifique como um profissional de saúde e que possa optar por atividades a nivel individual, grupal, insticucional e/ou comunitário.

3. Maior Enfasse tambem na pesquisa e ens trabalhos de extensajo.

4. Plancjamento anual, conjunto das acividades que integram as diferences áreas.

$S$. Incentivo i monografia como forma de preencher lacunat de imteresse do alano que nzo estžo suficientementie exploradis no longo do curno.

6. Criaçāo de um servico inserdisciplinar com o objetivo de oferecer aos alunos atividades práticas onde eles postam utufruir das diferentet etpecializapöes do cotpo docente. 